\title{
Empirical Research on Mathematical Modelling
}

\author{
Rolf Biehler • Dominik Leiss
}

Published online: 5 February 2010

(C) GDM 2010

Introducing and fostering the teaching of mathematical modelling and applications is a long-standing concern in mathematics education. Already in the days of the New Math reform, applications and modelling were an international concern. For instance, the first issue of Educational Studies in Mathematics in 1968 was devoted to this topic collecting contributions of a conference with the title "Teaching mathematics so as to be useful" (Freudenthal 1968). The paper of Pollak (1979) that he presented at ICME 3 in Karlsruhe 1976 was a landmark, often quoted until today. In the German speaking countries, the 1976 conference in Klagenfurt on "Anwendungsorientierte Mathematik" (Dörfler and Fischer 1976) was an early supporting event. The creation of the ICTMA community dates back to 1983 and is another land mark in this development with its biannual conferences.

More recent, the ICMI Study 14 (Blum et al. 2007) provides an excellent overview of the international state of the art. Many contributions in these conferences and studies are constructive in nature: They develop courses, examples, assessment schemes and so on. The number of empirical research papers however is also growing. The study document of the ICMI study summarises the still needed research by means of detailed research questions in the following nine domains. We are quoting some specific and some general research questions (see Blum et al. 2002, p. 155-167, for more details):

R. Biehler $(\bowtie)$

Universität Paderborn, Institut für Mathematik, Warburger Str. 100, 33098 Paderborn, Deutschland e-mail: biehler@math.uni-paderborn.de

D. Leiss

Leuphana Universität Lüneburg, Institut für Mathematik, Scharnhorststraße 1, 21335 Lüneburg, Deutschland

e-mail: leiss@me.com 
(1) Epistemology (e.g. "What are the process components of modelling? What is meant by or involved in each?"; loc.cit, p. 159)

(2) Application problems ("What does research have to tell us about the significance of authenticity to students' acquisition and development of modelling competency?"; p. 160)

(3) Modelling abilities and competencies (e.g. "Can specific subskills and subcompetencies of "modelling competency" be identified?"; p.160)

(4) Beliefs, attitudes and emotions (e.g. "Can modelling effectively contribute towards promoting views of mathematics that extend beyond transmissive techniques to its role as a tool for structuring other areas of knowledge?"; p. 162)

(5) Curriculum and goals ("What would be an appropriate balance-in terms of attention, time and effort between applications and modelling activities and other mathematical activities in mathematics classrooms at different educational levels?"; p. 162)

(6) Modelling pedagogy (e.g. "What are the areas of greatest need in supporting the design and implementation of courses with an modelling focus?"; p. 164)

(7) Sustained implementation (e.g. "What are the requirements for developing a mathematical modelling environment in traditional courses at school or university?"; p. 165)

(8) Assessment and evaluation (e.g. "What are the possibilities or obstacles when assessing mathematical modelling as a process (instead of a product)?"; p. 166)

(9) Technological impacts (e.g. "What important aspects of modelling are touched upon by the technological environment?"; p. 167)

Partly influenced by research results from these domains the implementation in curricula and everyday classroom practice has been varying over time and across countries. Without doubt, the international PISA study has supported a more extensive implementation of mathematical modelling in schools, as modelling is considered as one of the most important components of mathematical literacy (OECD 2003). As a result, in some countries, including Germany (cf. Klieme et al. 2003), national standards have taken up this concern and consider mathematical modelling as one of the central mathematical competencies to be developed at school level (cf. Niss 2003; Blomhøj and Jensen 2007).

Parallel to these societal and curricular developments, a growing body of empirical research on mathematical modelling is emerging. In Germany, several research projects have been created that focus on studying how students solve mathematical modelling problems and on the instructional strategies for fostering mathematical modelling. This research picks up the question what we understand by "mathematical modelling competency", how this competence can be assessed under classroom conditions, and how this competence can be conceptualised and measured paying attention to standards in cognitive psychology and psychometrics.

The current special issue of the Journal für Mathematikdidaktik (JMD) was motivated by the intention to make research approaches and research results of projects based in Germany better known internationally. The issue editors invited contributions from Germany and contributions from projects in neighbouring countries, such as from the research group of Lieven Verschaffel in Belgium and of Kurt Reusser in Switzerland, who have done internationally influential interdisciplinary research on modelling and word problems combining perspectives from mathematics education and educational psychology. Due to limitations of space and time, some contributions that were originally invited for this issue will be published in future issues of this journal.

The seven contributions of this issue can be grouped into 3 categories. 


\section{Studies on Real World Oriented Word Problems}

In the first two articles the authors describe word problems as a continuing concern and starting point for mathematical modelling. These problems are important both because they represent the current main part of modelling tasks that are used in daily lessons and because they can be seen as a kind of bridging item between intra-mathematical tasks and authentic modelling tasks. The main activities of students solving these kind of tasks are analysed and the impact of working with word problems for solving modelling tasks are discussed.

Lieven Verschaffel, Wim Van Dooren, Brian Greer, and Swapna Mukhopadhyah: Reconceptualising word problems as exercises in mathematical modelling.

Esther Brunner, Christine Pauli, Kurt Reusser: Understanding-oriented mathematics instruction using the example of solving a word problem.

\section{Studies on Competencies Related to Authentic Modelling Problems}

If more ore less artificial word problems represent one side of a spectrum of modelling tasks than authentic modelling problems will represent the other extreme of this spectrum (cf. Kaiser 1995). The two articles in this category show that it is possible, instructive, and interesting for students to deal with authentic problems even if there are a variety of difficulties in the solution processes.

Gabriele Kaiser, Björn Schwarz: Authentic modelling problems in mathematics educationexamples and experiences.

Matthias Ludwig, Binyan Xu: A comparative study of modelling competencies among Chinese and German students.

\section{Studies Focusing on the Influence of Specific Aspects of Instructional Design and of Students' Thinking Styles on Competencies in the Mathematical Modelling Process}

The articles in this category analyse the influence of specific psychological, cognitive, and metacognitive factors for the modelling process of students: thinking styles as an individual aspect of learners, the situation model as the central step in the process of understanding a modelling tasks, and heuristic worked examples as a helpful tool for supporting students' learning.

Rita Borromeo Ferri: On the influence of mathematical thinking styles on learners' modelling behaviour.

Dominik Leiss, Stanislaw Schukajlow, Werner Blum, Rudolf Messner, Reinhard Pekrun: The role of the situation model in mathematical modelling - task analyses, student competencies, and teacher interventions.

Luzia Zöttl, Stefan Ufer, Kristina Reiss: Modelling with heuristic worked examples in the KOMMA learning environment. 
We as issue editors are confident that the contributions of this issue will provide interesting and stimulating insights into students' working on mathematical modelling problems.

Rolf Biehler, Dominik Leiss

Issue Editors

\section{References}

Blomhøj, M., \& Jensen, T. H. (2007). What's all the fuss about competencies? In W. Blum, P. Galbraith, H.-W. Henn, \& M. Niss (Eds.), New ICMI study series. Modelling and applications in mathematics education (pp. 45-56). New York: Springer.

Blum, W., Galbraith, P., Henn, H.-W., \& Niss, M. (2002). ICMI study 14: applications and modelling in mathematics education-discussion document. Educational Studies in Mathematics, 51(1-2), 149171.

Blum, W., Galbraith, P., Henn, H.-W., \& Niss, M. (Eds.), (2007). Modelling and applications in mathematics education. New ICMI study series. New York: Springer.

W. Dörfler \& R. Fischer (Eds.), (1976). Anwendungsorientierte Mathematik in der Sekundarstufe II. Vorträge des 1. Kärntner Symposions für „Didaktik der Mathematik“. Klagenfurt: Heyn.

Freudenthal, H., (1968). Why to teach mathematics so as to be useful. Educational Studies in Mathematics, $1(1), 3-8$.

Kaiser, G. (1995). Realitätsbezüge im Mathematikunterricht. Ein Überblick über die aktuelle und historische Diskussion. In G. Graumann, T. Jahnke, G. Kaiser, \& J. Meyer (Eds.), Materialien für einen realitätsbezogenen Mathematikunterricht (Vol. 2, pp. 66-84). Hildesheim: Franzbecker.

Klieme, E., Avenarius, H., Blum, W., Döbrich, P., Gruber, H., Prenzel, M., Reiss, K., Riquarts, K., Rost, J., Tenorth, H.-E., \& Vollmer, H. (2003). Zur Entwicklung nationaler Bildungsstandards - Eine Expertise. In BMBF (Ed.), Zur Entwicklung nationaler Bildungsstandards (pp. 7-174). Bonn: Bundesministerium für Bildung und Forschung.

Niss, M. (2003). Mathematical competencies and the learning of mathematics: The Danish KOM project. In A. Gagtsis \& S. Papastavridis (Eds.), 3rd Mediterranean conference on mathematical education (pp. 115-124). Athens: The Hellenic Mathematical Society.

OECD (2003). The PISA 2003 assessment framework: mathematics, reading science and problem solving knowledge and skills. Paris: OECD.

Pollak, H. O. (1979). The interaction between mathematics and other school subjects. In International Commission on Mathematical Instruction (ICMI) (Ed.), New trends in mathematics teaching. (Vol. IV, pp. 232-248). Paris: UNESCO. 